\title{
A novel scoring system for prediction of esophageal varices in critically ill patients
}

This article was published in the following Dove Press journal:

Clinical and Experimental Gastroenterology

\author{
Amr Shaaban Hanafy' \\ Rehab Badawi ${ }^{2}$ \\ Mohammad Abdelkhalik \\ Atia Basha ${ }^{3}$ \\ Amal Selim ${ }^{4}$ \\ Mohamed Yousef ${ }^{2}$ \\ Sally Elnawasany ${ }^{2}$ \\ Loai Mansour ${ }^{2}$ \\ Reham Abdelkader \\ Elkhouly ${ }^{2}$ \\ Nehad Hawash ${ }^{2}$ \\ Sherief Abd-Elsalam² \\ 'Internal Medicine Department, \\ Hepatology Division, Zagazig \\ University, Zagazig, ${ }^{2}$ Tropical Medicine \\ Department, Tanta University, Tanta, \\ ${ }^{3}$ Diagnostic Radiology Department, \\ Zagazig University, Zagazig, ${ }^{4}$ Internal \\ Medicine Department, Tanta \\ University, Tanta, Egypt
}

Correspondence: Sherief Abd-Elsalam Tropical medicine Department, Tanta University Hospital, El Geish Street, Tanta, Gharbia Governorate, Egypt

Tel +201095159522

Email Sherif_tropical@yahoo.com
Background and aims: Patients with advanced systemic illness or critically ill patients may present with upper gastrointestinal tract (GIT) bleeding which may need endoscopic intervention; however, this may expose them to unnecessary endoscopy. The aim was to validate a novel scoring system for risk stratification for urgency of GIT endoscopy in critically ill patients.

Methods: This is an observational study conducted from January 2013 to January 2016 to analyze 300 patients with critical medical conditions and presenting with upper gastrointestinal bleeding. Meticulous clinical, laboratory, and sonographic evaluations were performed to calculate Glasgow Blatchford score (GBS) and variceal metric score for risk stratification and prediction of the presence of esophageal varices (OV). Finally, this score was applied on a validation group $(\mathrm{n}=100)$.

Results: The use of GBS and variceal metric scores in critically ill patients revealed that patients who showed a low risk score value for OV ( $0-4$ points) and GBS $<2$ can be treated conservatively and discharged safely without urgent endoscopy. In patients with a low risk for varices but GBS >2, none of them had OV on endoscopy. In patients with intermediate risk score value for OV (5-8 points) and with GBS $>2,33.33 \%$ of them had varices on endoscopy. In patients with high risk score value for varices (9-13) and GBS >2, endoscopy revealed varices in $94.4 \%$ of them. Finally, in patients with very high risk score for varices (14-17), endoscopy revealed varices in $100 \%$ of them.

Conclusion: GBS and variceal metric score were highly efficacious in identifying critically ill patients who will benefit from therapeutic endoscopic intervention.

Keywords: noninvasive, upper endoscopy, variceal metric score, Glasgow Blatchford, critically ill

\section{Introduction}

Patients with advanced systemic illness could be presented with an acute attack of hematemesis which may need endoscopic intervention; however, this may expose the brittle patients to serious life threatening adverse effects if performed unnecessarily.

Cardiopulmonary complications related to sedation account for nearly $60 \%$ of endoscopic adverse events; ${ }^{1}$ patients at high risk include those who are old and with a preexisting cardiopulmonary disease. Endoscopy-related risk factors for hypoxia include difficult intubation, a prolonged procedure, and a patient in the prone position. ${ }^{2}$ Transient bacteremia and infective endocarditis rates are low. ${ }^{3,4}$

Clinically significant bleeding after endoscopy is a rare adverse event. Diagnostic endoscopy can be performed when platelet count is at least $20,000 / \mathrm{mL}$, and a count of at least $50,000 / \mathrm{mL}$ should be considered before taking biopsies. ${ }^{5}$ 
Causes of upper gastrointestinal bleeding (UGIB) in critically ill patients include variceal and acid-related disorders. The risk of bleeding increases with an age $\geq 65$ years, prolonged use of nonsteroidal anti-inflammatory drugs (NSAIDs), ${ }^{6}$ polymorphism of CYP $2 \mathrm{C} 9,{ }^{7}$ associated Helicobacter pylori infection, and concomitant use of steroids, anticoagulants, and bisphosphonates.

Stress-related mucosal damage is the most common cause of UGIB in critically ill patients; the risk is increased in mechanical ventilation $>48$ hours, platelets $<50.000 / \mathrm{mm}^{3}$, international normalized ratio (INR) $>1.5$, sepsis, shock, severe burns, and malnutrition. ${ }^{8}$

Bleeding esophageal varices (OV) is the second most common cause of UGIB. ${ }^{9}$ In Egypt, OV represented $70 \%$ of UGIB followed by nonvariceal causes (26\%) and obscure causes $(4 \%) ;{ }^{10}$ other less common cases of UGIB are Mallory-Weiss syndrome (15\%) and vascular lesions such as aortoenteric fistula and Dieulafoy lesion (2\%-3\%). ${ }^{6}$

As regards to endoscopy in special situations such as pregnancy, endoscopy is not contraindicated. Variceal hemorrhage is uncommon, although it may occur in patients with underlying cirrhosis, and endoscopic band ligation is the favored intervention. ${ }^{11,12}$

As regards to patients on anticoagulants or antiplatelet therapy, hemorrhage may occur immediately at the time of endoscopy or delayed up to 2 weeks following the procedure. ${ }^{13}$ So, in diagnostic procedures without biopsy such as biliary or pancreatic stenting and diagnostic endosonography, clopidogrel can be continued; warfarin can be also be continued if INR is within therapeutic range but if $\leq 5$ the daily dose is reduced. ${ }^{14}$

In variceal therapy, in high-risk patients (metal mitral valve replacement, valve replacement with atrial fibrillation [AF], AF with mitral stenosis, venous thromboembolism $<3$ months), warfarin should be stopped 5 days before the procedure and low-molecular-weight heparin (LMWH) need to be started 2 days after warfarin withdrawal and then stopped the day of procedure, with warfarin introduced at the evening after the completion of the procedure; LMWH should be started the next day till adequate INR is achieved. ${ }^{14}$

However, regarding patients with coronary artery disease (CAD), peptic ulcer and bleeding OV are the most common causes of UGIB. Ventricular arrhythmias and myocardial ischemia were common complications after endoscopy in patients with $\mathrm{CAD}$, especially with concomitant congestive heart failure. ${ }^{15}$

In patients on dialysis, endoscopy is not contraindicated when it is highly indicated, and common causes are gastric antral vascular ectasia (GAVE) followed by gastroduodenal ulcer. GAVE was improved when hemodialysis was changed into continuous ambulatory peritoneal dialysis. ${ }^{16,17}$

In elderly patients, risks arising during sedation are mainly due to hypotension, hypoxia, arrhythmias, and aspiration. ${ }^{18}$

In patients with chronic obstructive pulmonary disease (COPD), due to inadequate sedation, patients may be exposed to the risk of elevated blood pressure, angina, and myocardial infarction. ${ }^{19}$

The study aimed to propose a noninvasive scoring system to identify OV in critically ill patients allowing prompt endoscopic intervention for the patients in urgent need for this intervention. At the same time; exclusion of nonvariceal causes to avoid unnecessary endoscopy and its related adverse events till they pass their medical critical illness safely.

\section{Methods}

\section{Patient selection}

This is an observational study carried out during the period from January 2013 to January 2016; out of 853 patients, we selected 300 patients with other comorbidities presented with UGIB. They were admitted to the intensive care unit (ICU) unit, Gastroenterology Section, Internal Medicine Department, Zagazig University, which is a tertiary referral center. Inclusion criteria were patients with UGIB and concomitant medical critical illness such as cardiopulmonary and renal diseases which make endoscopy difficult and risky. Patients on nonselective beta blockers, portal vein thrombosis, and previous endoscopic or surgical intervention for portal hypertension were excluded.

The study was approved by the ethical review board of Zagazig University. Although the study depended on investigations which were mandatory for patients presenting with UGIB, an oral consent was obtained from all patients, and written consent was obtained from patients who were able or from the relatives of the other patients.

Patients were evaluated and prepared for 12 hours before endoscopy by thorough clinical examination, including vital signs, signs of portal hypertension, signs of liver cell failure, and any signs of renal, cardiac, or respiratory diseases were documented. Also, routine investigations were performed for them including liver function tests, coagulation profile, renal function tests, and complete blood count. For each patient Child-Turcotte-Pugh score (CTP) was calculated. ${ }^{20}$

\section{Diagnostic procedures}

Glasgow Blatchford score (GBS) was used for risk stratification of UGIB, as shown in Table 1. A low-risk category is defined as GBS of $<2$. A score of 6 or more was associated with a greater than $50 \%$ risk which needs endoscopic intervention. $^{21}$ 
Abdominal ultrasonography was performed for all patients, stressing on the presence of cirrhotic echo pattern or the presence of ascites. Also, portal vein diameter (PVD) $>13$ $\mathrm{mm}$ indicated portal hypertension. ${ }^{22}$ The spleen was evaluated for its bipolar diameter. A length $>130 \mathrm{~mm}$ indicated enlargement with associated splenic vein diameter $>10 \mathrm{~mm}$ denoted portal hypertension..$^{23,24}$

Color Doppler ultrasound was performed by real-time portable ultrasound equipment (SonoScape S9) consisting

\section{Table}

\begin{tabular}{ll}
\hline $\begin{array}{l}\text { Blood urea, } \mathbf{~ m g} \% \\
<39\end{array}$ & 0 \\
$39-48$ & 2 \\
$49-59$ & 3 \\
$60-149$ & 4 \\
$>150$ & 6 \\
Hb for men (g/dL) & \\
$\geq 13$ & 0 \\
I2-12.9 & 1 \\
$10-11.9$ & 3 \\
$<10$ & 6 \\
Hb for women (g/dL) & \\
$\geq 12$ & 0 \\
I0-II.9 & 1 \\
$<10$ & 6 \\
Systolic blood pressure $(\mathbf{m m H g})$ & \\
$\geq 110$ & 0 \\
I00-109 & 1 \\
$90-99$ & 2 \\
$<90$ & 3 \\
Other markers & \\
Pulse $>100$ (b/min) & \\
Melena & 1 \\
Syncope & 1 \\
Hepatic & \\
Cardiac & 2 \\
Renal & 2 \\
\hline Ab & 2 \\
\hline
\end{tabular}

Abbreviation: $\mathrm{Hb}$, hemoglobin. of a color Doppler and a pulsed Doppler device working at 3.5 $\mathrm{MHz}$ frequency. ${ }^{25}$

Congestive index of the portal vein (PVCi) was calculated as the ratio between the portal vein cross-sectional area $\left(\mathrm{cm}^{2}\right)$ and the blood flow velocity $(\mathrm{cm} / \mathrm{s})$. A cutoff value $>0.14$ $\mathrm{cm} \times \mathrm{sec}$ was selected, which has a sensitivity of $70 \%$ and specificity of $64.9 \%$ for the risk of bleeding from OV. ${ }^{26,27}$

The intraparenchymal renal artery resistance index (RARI) was calculated as follows: $\mathrm{A}-\mathrm{B} / \mathrm{A}$, where $\mathrm{A}$ is the peak systolic velocity and $B$ is the end diastolic velocity. A cutoff value $>0.7$ was selected as $70 \%$ probability for the existence of $\mathrm{OV}^{28}$

Variceal metric score composed of clinical, laboratory, and radiological variables in order to minimize the hazards of unnecessary exposure to endoscopy in high-risk patients, as shown in Table 2. The total score is 17: low risk ( $\leq 4)$, intermediate risk (5-8), high risk (9-13), and very high risk (14-17).

Upper gastrointestinal (GI) endoscopy was done for patients enrolled in the study. If OV were present, their size was graded as I-IV using the Paquet grading system. ${ }^{29}$

\section{Validation}

Further, we aimed to assess the predictive power of the scoring model clinically through evaluation in another cohort composed of 100 patients in the period from January 2016 to January 2017 who presented with other comorbidities and UGIB. The methods used for selection were similar to those of the study patients.

\section{Statistical analysis}

Data were analyzed using PASW Statistics 18. Continuous variables were summarized as mean \pm standard deviation and standard of error (SE) when appropriate. Chi-square test was used for categorical variables. The Student's $t$-test and analysis of variance were appropriately used. Correlation

Table 2 OV metric score for noninvasive prediction of esophageal varices

\begin{tabular}{|c|c|c|c|c|}
\hline Points & 0 & $\mathbf{I}$ & 2 & 3 \\
\hline \multicolumn{5}{|l|}{ Clinicolaboratory criteria } \\
\hline I-Splenomegaly by palpation & Absent & Present & & \\
\hline 2-Child Pugh score & Score $<7$ & & Score $>7$ & \\
\hline 3- AST/ALT ratio & $<1$ & $>1$ & & \\
\hline 4- Platelet count & $>150 \times 10^{3} / \mathrm{uL}$ & $100-150 \times 10^{3} / \mathrm{uL}$ & $80-100 \times 10^{3} / \mathrm{uL}$ & $<80 \times 10^{3} / \mathrm{uL}$ \\
\hline \multicolumn{5}{|l|}{ Ultrasonographic criteria } \\
\hline I-PVD (mm) & $<13$ & $13-15$ & $>15$ & \\
\hline 2-SBD (cm) & $<13$ & $13-18$ & $>18$ & \\
\hline 3-SVD (mm) & $<10$ & $10-12$ & $12 \mathrm{~mm}$ with hilar varices & \\
\hline \multicolumn{5}{|l|}{ Doppler criteria } \\
\hline I-PVCi (cm×sec) & $<0.07$ & $0.07-0.14$ & $>0.14$ & \\
\hline 2-RARI & $<0.68$ & $0.68-0.7$ & $>0.7$ & \\
\hline
\end{tabular}

Abbreviations: ALT, alanine transaminase; AST, aspartate transaminase; PVD, portal vein diameter; SBD, splenic bipolar diameter; SVD, splenic vein diameter; PVCi, portal vein congestive index; RARI, renal artery resistive index; OV, esophageal varices. 
of risk factors associated with OV was determined using Pearson rank correlation.

A scoring system was postulated for noninvasive prediction of $\mathrm{OV},{ }^{30}$ and points were assigned to each variable based on the magnitude of its regression coefficient; the one with the smallest $\beta$ coefficient was given 1 point and others were given points according to the strength of their $\beta$ coefficient when compared to the smallest. The collected points were grouped into predefined categories for the risk of OV: low $(<15 \%)$, intermediate $(15 \%-49 \%)$, high $(50 \%-79 \%)$, and very high $(>80 \%){ }^{31}$

A receiver operating characteristic (ROC) analysis was carried out to examine the diagnostic utility of the constructed scoring model. The cutoff point for each variable is the point with the highest sensitivity and specificity in ROC curve analysis.

\section{Results}

Three hundred critically ill patients with UGIB were evaluated for priority of upper GI endoscopy.

They were 108 females (36\%) and 192 males (64\%), with a mean age of $53.7 \pm 12$ years. A total of 144 patients had hepatic diseases (48\%), mostly due to hepatitis $\mathrm{C}$ virus ( $\mathrm{HCV}, \mathrm{n}=120)$, hepatitis $\mathrm{B}$ virus (HBV, $\mathrm{n}=16)$, and combined $\mathrm{HCV}$ and HBV $(\mathrm{n}=8)$. A total of 78 patients had cardiac diseases (25.8\%), such as Acute coronary syndrome $(n=65)$, cardiogenic shock due to dilated cardiomyopathy $(n=3)$, stuck artificial valve $(n=6)$, and four patients with aortic and mitral valve replacement presented with melena due to warfarin toxicity. Sixty patients had chronic renal disease (20\%). Ten females were pregnant and six of them had hepatic disorders (Figure1).

On initial clinical evaluation, the mean systolic blood pressure was $106.8 \pm 22.7 \mathrm{mmHg}$. Splenomegaly by palpation was documented in 144 patients (47.4\%), ascites and signs of parenchymatous liver cell failure were seen in 78 patients $(25.8 \%)$.

The laboratory data included a mean hemoglobin of $8.47 \pm 2.3 \mathrm{~g} / \mathrm{dL}$, platelet count $128 \pm 59 \times 10^{3} / \mu \mathrm{L}$, serum albu$\min 3.07 \pm 0.78 \mathrm{~g} / \mathrm{dL}$, total bilirubin $1.42 \pm 0.56 \mathrm{mg} / \mathrm{dL}$, creatinine $1.74 \pm 1.6 \mathrm{mg} / \mathrm{dL}$, and urea $52.1 \pm 23.7 \mathrm{mg} / \mathrm{dL}$. Mean value of the CTP score was 5.8 \pm 1.8 . CTP class B was seen in 96 patients $(31.8 \%)$, and class $C$ was seen in 14 patients (4.6\%).

Bedside portable ultrasonography including color Doppler evaluation confirmed liver cirrhosis and splenomegaly in 144 patients, with a mean PVD of $12.4 \pm 2.3 \mathrm{~mm}$, PVD $>13 \mathrm{~mm}(\mathrm{n}=144,47.4 \%)$; SVD $8.46 \pm 2.7 \mathrm{~mm}$, SVD $>10$ $\mathrm{mm}(\mathrm{n}=138,45.7 \%)$; PVCi 0.116 $\pm 0.05, \mathrm{PVCi}>0.14(\mathrm{n}=132$, $43.7 \%)$; RARI $0.698 \pm 0.126$, RARI $>0.7(n=150,49.7 \%)$ (Figures 2 and 3).

GBS was calculated to determine the priority for intensive care management and endoscopy. The mean GBS was 11.6 \pm 6.5 . Score was 0 in six female patients $(2 \%)$ and two females were pregnant in the first trimester, and all of them discharged safely as outpatients because their GBS was 0 .

Thirty $(10 \%)$ patients with UGIB showed GBS score 1 , with a mean age $50.6 \pm 11.5$ years. They were followed for 3 days in ICU and discharged for outpatient management and follow-up.

A score of 3-6 was seen in 48 patients (16\%). GBS $>6$ was seen in 216 patients $(72 \%)$, and their characteristics are described in Table 3.

The study patients were classified into four subgroups according to their GBS score: GBS $0(n=6)$, GBS $1-2(n=30)$, GBS 3-6 $(n=48)$, GBS $>6(n=216)$. There was a significant statistical difference among the four subgroups with regard to systolic blood pressure, radial pulse, hemoglobin, platelet count, INR, albumin, total bilirubin, AST, creatinine, and blood urea. The occurrence of melena and pre-syncope were more frequent in the subgroup with GBS $>6(p=0.000)$ (Table 3). The ultrasonographic and Doppler criteria in the

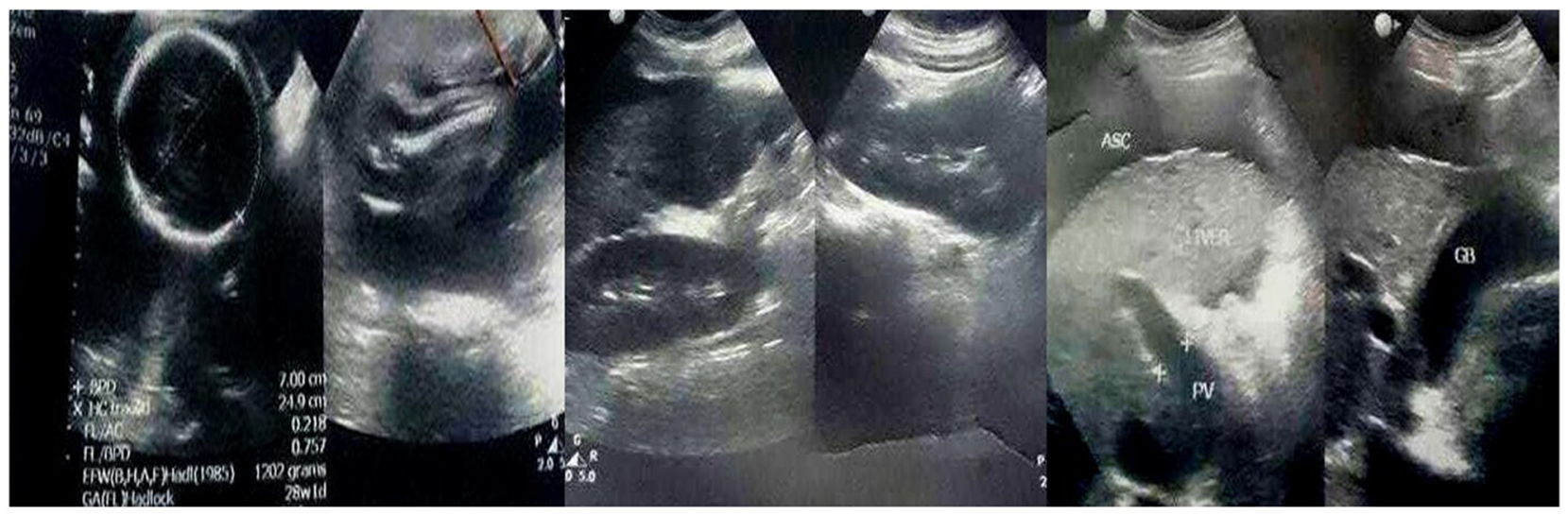

Figure I Abdominal ultrasonography of young adult pregnant female presenting with hematemesis showed cirrhotic liver with moderate ascites and intrauterine pregnancy. 


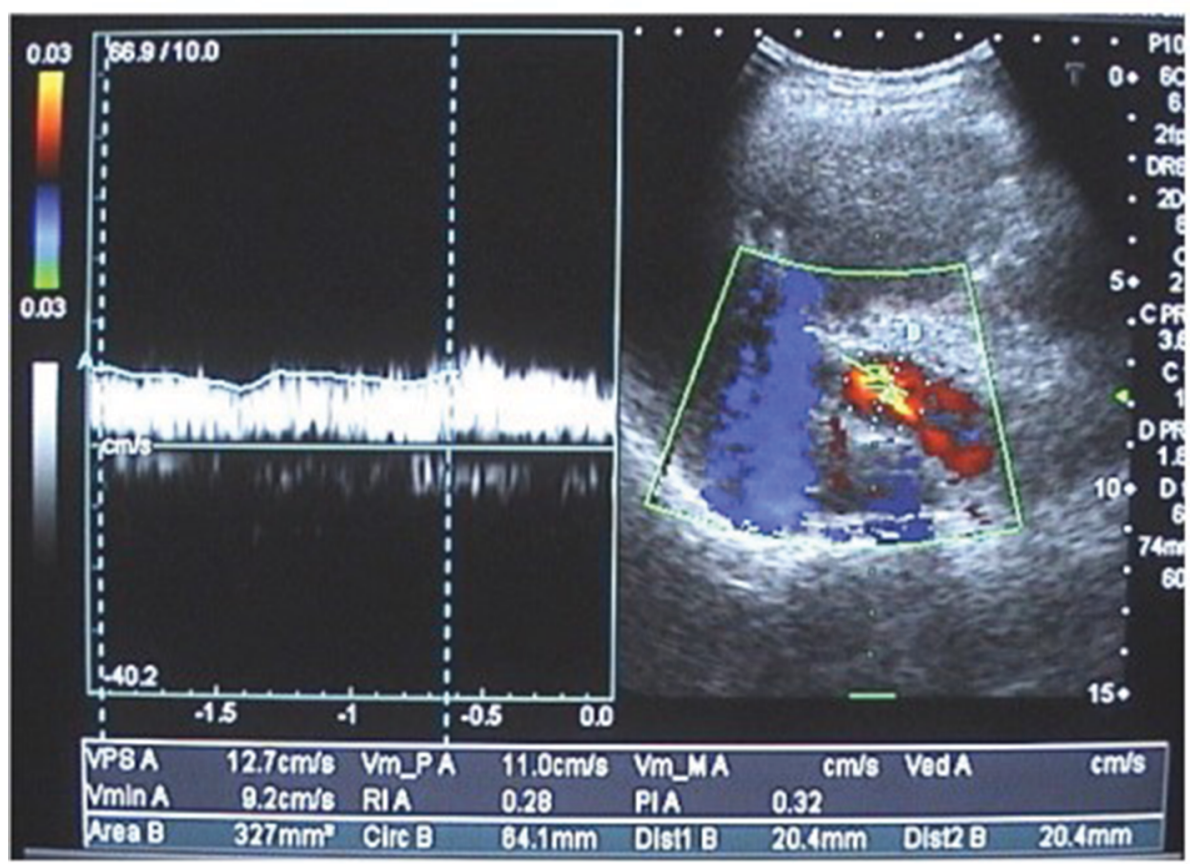

Figure 2 Colour Doppler sonography of the portal vein with maximum flow velocity of $12.7 \mathrm{~cm} / \mathrm{s}$, minimum flow velocity of $9.2 \mathrm{~cm} / \mathrm{s}$, and mean flow velocity of $\mathrm{II} \mathrm{cm} / \mathrm{s}$. Portal vein cross-sectional area equals $20.4 \mathrm{~mm}$.

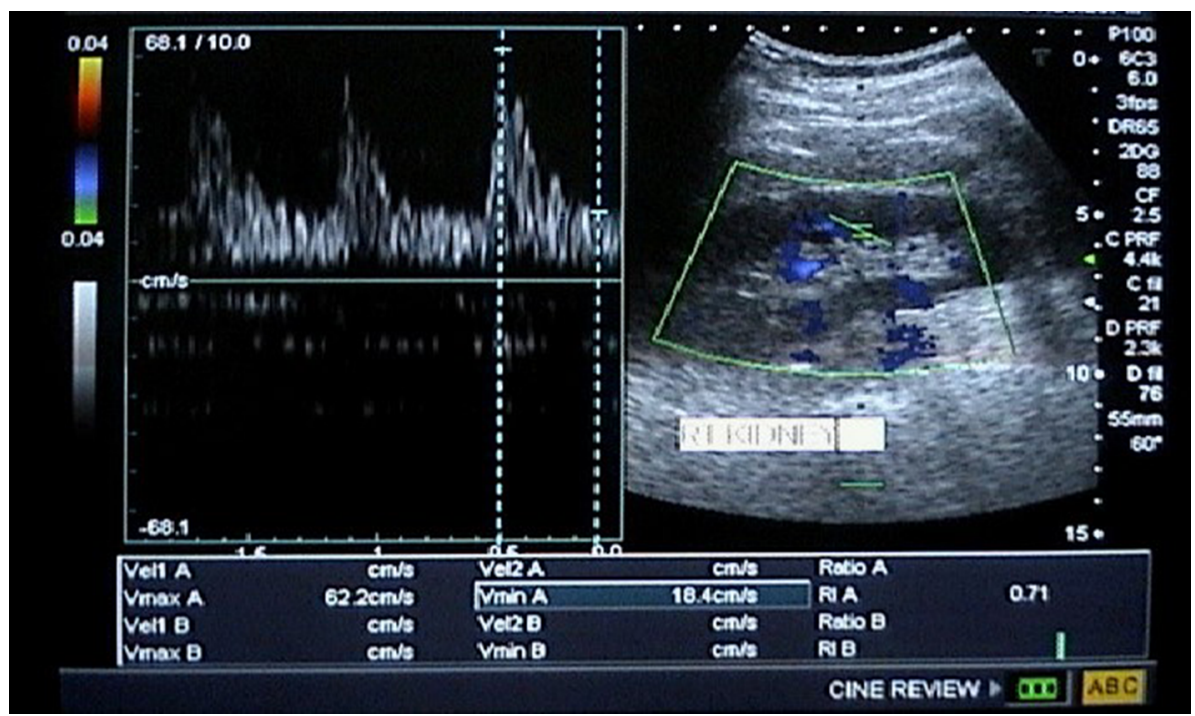

Figure 3 Doppler sonography of the right kidney showing increased renal arteriolar resistive index with a value of 0.71 .

four subgroups showed a significant statistical difference with higher values in patients with GBS $>6$ and with mean OV score 8.82 $\pm 5.7(p=0.000)$, as shown in Table 3 .

\section{Approach to the critically ill patients according to GBS and OV metric score}

Patients with GBS 0 and $<2$ and with OV metric score mean value of $2.5 \pm 0.7$, i.e., no risk of hemodynamic instability by GBS and low risk for OV, were followed up for 2 days in ICU and kept on fluid therapy and proton pump infusion with initial loading dose of $80 \mathrm{mg}$ and then continuous infusion at $8 \mathrm{mg}$ per hour for 72 hours. Then the patients were discharged safely and followed up as outpatients for 1 month without adverse clinical events. Endoscopy was performed again after 1 month and revealed no abnormalities.

Patients with GBS 3-6 and OV score mean value of $3 \pm 0.9$ were at low risk for OV but with high priority for endoscopic intervention as GBS >2, hence they were kept on 
Table 3 Baseline clinical, laboratory, ultrasonographic, and Doppler criteria of the patients under study stratified by their GBS value

\begin{tabular}{|c|c|c|c|c|c|}
\hline Data (criteria) & GBS $0(N=6)$ & GBS $<2(N=30)$ & GBS 3-6 $(\mathrm{N}=48)$ & GBS $>6(N=216)$ & $P$-value \\
\hline Age (years) & $44.3 \pm 16.3$ & $50.6 \pm 11.5$ & $53.1 \pm 14.2$ & $54.4 \pm 11.3$ & 0.4 \\
\hline$M / F$ & $0 / 6$ & $18 / 12$ & $36 / 12$ & $138 / 78$ & 0.08 \\
\hline Systolic (mmHg) & $120.2 \pm 3.2$ & $110 \pm 12.2$ & $100.8 \pm 2.5$ & $86.5 \pm 7.8$ & 0.008 \\
\hline Pulse (b/min) & $78.4 \pm 4.8$ & $84.8 \pm 4.3$ & $95.4 \pm 11.1$ & $101.2 \pm 20.8$ & 0.005 \\
\hline $\mathrm{Hb}(\mathrm{gm} / \mathrm{dL})$ & $12.2 \pm 0.4$ & $11.7 \pm 0.62$ & $9.9 \pm 2.9$ & $7.6 \pm 1.5$ & 0.000 \\
\hline Platelets $(103 / \mu \mathrm{L})$ & $148 \pm 7.2$ & $168.2 \pm 18.1$ & $192.5 \pm 56.7$ & $107.6 \pm 50.8$ & 0.000 \\
\hline INR & $I . I \pm 0.1$ & $1.02 \pm 0.04$ & $1.9 \pm 0.78$ & $1.62 \pm 0.7$ & 0.04 \\
\hline Albumin $(\mathrm{gm} / \mathrm{dL})$ & $3.5 \pm 0.4$ & $3.9 \pm 0.26$ & $3.85 \pm 0.28$ & $2.8 \pm 0.7$ & 0.03 \\
\hline Total bilirubin $(\mathrm{mg} / \mathrm{dL})$ & $0.75 \pm 0.2$ & $0.93 \pm 0.06$ & $1.07 \pm 0.17$ & $1.58 \pm 0.58$ & 0.04 \\
\hline AST(IU/L) & $37 \pm 0.2$ & $37.2 \pm 7.1$ & $42.2 \pm 8.1$ & $61.2 \pm 24.5$ & 0.02 \\
\hline ALT(IU/L) & $33 \pm 0.3$ & $34.8 \pm 3.5$ & $40.8 \pm 7.5$ & $55.6 \pm 19$ & 0.058 \\
\hline Creatinine (mg/dL) & $0.9 \pm 0.2$ & $0.91 \pm 0.1$ & $1.12 \pm 0.36$ & $2.02 \pm 0.85$ & 0.02 \\
\hline Urea (mg/dL) & $30.1 \pm 0.23$ & $28 \pm 6$ & $33 \pm 6.2$ & $61.3 \pm 21.7$ & 0.03 \\
\hline Melena & 0 & 0 & 18 & 192 & 0.001 \\
\hline Pre-syncope & 0 & 0 & 0 & 104 & 0.001 \\
\hline GBS & 0 & I & $4.13 \pm 1.3$ & $15.1 \pm 3.9$ & 0.002 \\
\hline PVD & $11 \pm 0$ & $10.2 \pm 0.54$ & $10.2 \pm 0.6$ & $13.3 \pm 2.2$ & 0.02 \\
\hline SBD & $I I \pm 0$ & $10.5 \pm 5.1$ & I I. $5 \pm 8.4$ & $15.1 \pm 3.5$ & 0.03 \\
\hline SVD & $6 \pm 0$ & $5.9 \pm 0.46$ & $5.8 \pm 0.6$ & $9.5 \pm 2.6$ & 0.01 \\
\hline $\mathrm{PVCi}$ & $0.08 \pm 0$ & $0.07 \pm 0.01$ & $0.069 \pm 0.01$ & $0.134 \pm 0.05$ & 0.03 \\
\hline RARI & $0.6 \pm 0$ & $0.57 \pm 0.1$ & $0.58 \pm 0.03$ & $0.74 \pm 0.12$ & 0.04 \\
\hline OV score & $3 \pm 0$ & $2.5 \pm 0.7$ & $3 \pm 0.9$ & $8.82 \pm 5.7$ & 0.000 \\
\hline
\end{tabular}

Note: $P<0.05$ is considered statistically significant and are presented in bold.

Abbreviations: GBS, Glascow Blatchford score; PVD, portal vein diameter; SBD, splenic bipolar diameter; SVD, splenic vein diameter; PVCi , portal vein congestive index; RARI, renal artery resistive index; OV, esophageal varices; INR, international normalized ratio; Hb, hemoglobin.

fluid therapy, blood transfusion, and proton pump infusion. Endoscopy in these patients was done within 12 hours and revealed peptic ulcer disease (PUD) $(n=34)$, vascular ectasia $(n=8)$, and GAVE $(n=6)$ with no OV, and they were treated with argon plasma coagulation.

Patients with GBS $>6$ and with OV score mean value of $8.82 \pm 5.7$, i.e., intermediate to high risk for OV and high priority for endoscopy according to GBS, were given fluid therapy and blood transfusion. Endoscopy was done within 12 hours which revealed OV $(n=144)$ secured with rubber band ligation, portal hypertensive gastropathy (PHG) grade II-III $(\mathrm{n}=40)$ treated with argon plasma and beta blockers, PUD $(n=14)$, vascular ectasia $(n=2)$, and GAVE $(n=16)$ managed with argon plasma coagulation, as shown in Table 4.

\section{Evaluation of the patients under study according to their current illness, $\mathrm{OV}$, and GBS scores}

A total of 144 hepatic patients (48\%) presented with UGIB. All of them showed GBS $>6$, i.e., high risk of hemodynamic instability, and OV score $12.7 \pm 2.2$, i.e., high risk for OV, so endoscopy was performed which showed OV in 136 patients (94.4\%) $(p=0.000)$.
Seventy-eight cardiac patients (26\%) presented with UGIB, 18 patients with GBS 3-6 and 60 patients with GBS $>6$, and OV score 2.1 \pm 1.2 (SE). Endoscopy was performed which showed OV in only six patients $(7.6 \%)$ as the OV score indicated low risk $(p=0.000)$.

Sixty patients with chronic renal failure $(20 \%)$ presented with UGIB, six patients with GBS 3-6 and 54 patients with GBS $>6$, and OV score 7.7 \pm 3.1 . Endoscopy was performed which showed OV in 30 patients (50\%).

Eight patients with COPD (2.6\%) presented with UGIB, four patients with GBS 0 and four patients with GBS $1-2$, and OV score $1.7 \pm 0.2$, i.e., low risk. They were observed in ICU for 2 days and discharged as outpatients and were followed up for 1 month without adverse clinical events. Endoscopy was done 1 month after stabilization of their medical condition and it revealed no abnormalities.

Ten pregnant female patients $(3.3 \%)$ presented with UGIB, two patients with GBS 0, six patients with GBS 3-6, and two patients with GBS $>6$, and OV score $8.7 \pm 0.7$. Endoscopy was performed in eight patients due to intermediate risk of OV and high priority for endoscopy. The results showed OV in six patients (75\%) $(p=0.03)$ which were managed with rubber band ligation as shown in Table 5 . 
Table 4 Outcome of the patients under study according to GBS risk stratification

\begin{tabular}{lllll}
\hline & GBS $\mathbf{0}(\mathbf{N}=\mathbf{6})$ & GBS $<\mathbf{2}(\mathbf{N}=\mathbf{3 0})$ & GBS 3-6 (N=48) & GBS >6(N=2 I6) \\
\hline Outcome & -Discharge & -Discharge & I- Blood transfusion & I- Blood transfusion \\
& -Follow-up for & -Follow-up for I month & 2- PPI & 2-PPI+Glypressin \\
I month & - Endoscopy after I month & 3- Endoscopy & 3- Endoscopy \\
-Endoscopy after & is free & -PUD (34) & -PUD (I4) \\
Imonth is free & & -Vascular ectasia (8) & -Vascular ectasia (2) \\
& & -GAVE (6) & -PHG grade II-III (40) \\
& & & - GAVE (I6) \\
& & & - OV grade 2 (30) \\
& & & - OV grade 3 (68) \\
& & & - OV grade 4 (46) \\
\hline
\end{tabular}

Abbreviations: GBS, Glascow Blatchford score; PUD, peptic ulcer disease; PPI, proton pump inhibitors; GAVE, gastric antral vascular ectasia; PHG, portal hypertensive gastropathy; OV, esophageal varices.

Table 5 Correlation of GBS score with endoscopy among patients with critical illness

\begin{tabular}{|c|c|c|c|c|c|}
\hline & Hepatic (144) & Cardiac (78) & Renal (60) & COPD (8) & Pregnant (10) \\
\hline GBS $0(n=6)$ & 0 & 0 & 0 & 4 & 2 \\
\hline GBS I-2 $(n=4)$ & 0 & 0 & 0 & 4 & 0 \\
\hline GBS 3-6 $(n=30)$ & 0 & 18 & 6 & 0 & 6 \\
\hline GBS $>6 \quad(n=260)$ & 144 & 60 & 54 & 0 & 2 \\
\hline$P$-value & 0.000 & 0.043 & 0.02 & 0.4 & 0.38 \\
\hline OV score & $12.7 \pm 2.2$ & $2.1 \pm 1.2(\mathrm{SE})$ & $7.7 \pm 3.1$ & $1.7 \pm 0.2$ & $8.7 \pm 0.7$ \\
\hline \multicolumn{6}{|l|}{ Endoscopy } \\
\hline OV $(n=178)$ & 136 & 6 & 30 & Non & 6 \\
\hline No OV $(n=\mid 12)$ & 8 & 72 & 30 & Non & 2 \\
\hline$P$-value & 0.000 & 0.000 & 0.23 & - & 0.03 \\
\hline
\end{tabular}

Notes: The patients in each subgroup were stratified according to GBS score and chi-square test was used to detect the statistical significance according to GBS stratification in each subgroup, $p<0.05$ was considered as statistically significant and are shown in bold.

Abbreviations: GBS, Glascow Blatchford score; OV, esophageal varices; SE, standard of error.

\section{The predictive power of the OV score}

The predictive power of OV scoring system was evaluated in the study population by using ROC curve analysis. The area under the curve (AUC) was 0.993. The cutoff value of the score associated with highest sensitivity and specificity was 8 with a sensitivity of $98.5 \%$ and specificity of $76 \%$.

A total of 156 patients (52\%) showed an OV score value of $0-4$ ); of them 6 and 30 patients showed GBS score 0 and $<2$, respectively, and OV score $2.3 \pm 0.7$. Therefore, they were followed up in the ICU and discharged without endoscopy and followed up for 1 month as outpatients without any complications. The other 120 patients (77\%) showed GBS >2, so we performed GI endoscopy and as the OV score was 2.5 \pm 0.9 ), none of them showed OV, magnifying the predictive power of the score.

Six patients (2\%) showed an intermediate risk for OV (score 5-8).All of them showed GBS $>6$ and upper GI endoscopy revealed grade II OV in two patients (33.3\%).

Seventy-two patients (24\%) showed high risk for OV (score 9-13) and all of them showed GBS >6. Endoscopy was done which revealed OV in 68 patients (94.4\%); of them 20 patients showed grade II OV (29.4\%), 36 patients (53\%) grade III OV, and 12 patients (17.6\%) grade IV OV.

Sixty-six patients $(22 \%)$ had a very high risk for OV (score 14-17) and all of them showed GBS >6. Upper GI endoscopy was done and revealed OV in $66(100 \%)$ patients; of them 32 patients showed grade III OV (48.4\%) and 34 patients $(51.6 \%)$ showed grade IV OV, i.e., higher score values were associated with large size of OV.

There was a highly significant correlation between the GBS grade and the presence and size of varices only when associated with high OV metric score (Pearson's chi-square $t$-value $=53.85, p=0.000$ ), as shown in Figure 4. The clinical score was highly efficacious in predicting OV presence (Pearson's chi-square $t$-value $=175.3, p=0.000$ ), as shown in Table 6.

The presence of OV is negatively correlated with age $(r=-0.171, p=0.037)$ and platelet count $(r=-0.835, p=0.000)$. It is positively correlated with the presence of splenomegaly 
$(r=0.910, p=0.000)$, GBS $(r=0.711, p=0.000)$, CTP score $(r=0.790, p=0.000)$, and OV metric score $(r=0.939, p=0.000)$.

\section{Validation}

From a total of 300 patients who presented with UGIB, 100 patients (20 females, 80 males) were selected. Their main age was $46.2 \pm 3.4$ years. Thirty patients were suffering from hepatic diseases $(30 \%)$ due to HCV $(n=28)$ and HBV $(n=2)$; 50 patients from cardiac diseases $(50 \%) ; 10$ patients from chronic renal failure (10\%); and 10 patients from COPD $(10 \%)$.

On clinical evaluation; the mean systolic blood pressure was $95 \pm 15 \mathrm{mmHg}$. Splenomegaly by palpation was detected in 50 patients $(50 \%)$; ascites and signs of parenchymatous liver cell failure were documented in 20 patients $(20 \%)$.

The laboratory data included mean hemoglobin $7.45 \pm 1.7 \mathrm{~g} / \mathrm{dL}$, platelet count $135 \pm 43 \times 10^{3} / \mu \mathrm{L}$, albumin $3.34 \pm 0.23 \mathrm{~g} / \mathrm{dL}$, total bilirubin $1.22 \pm 0.34 \mathrm{mg} / \mathrm{dL}$, and

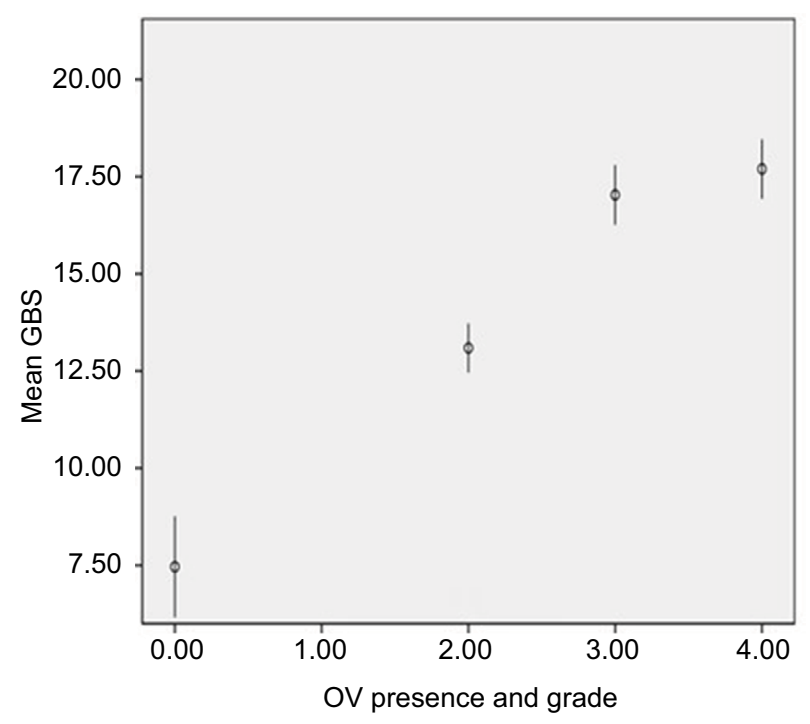

Figure 4 Correlation between OV presence and grade with GBS score value. Abbreviations: GBS, Glasgow Blatchford score; OV, esophageal varices. creatinine $1.6 \pm 0.7 \mathrm{mg} / \mathrm{dL}$. Bedside portable ultrasonography included color Doppler which revealed liver cirrhosis and splenomegaly in 50 patients with the mean PVD $11.7 \pm 1.9 \mathrm{~mm}, \mathrm{SVD} 8 \pm 2.2 \mathrm{~mm}$, PVCi $0.122 \pm 0.1$, and RARI $0.679 \pm 0.13$.

The OV score was applied on the validation group, and endoscopy was done in all patients to confirm the predictive role.

Among the 20 patients with GBS $=0$ and OV metric score $2.35 \pm 1.1$, endoscopy showed no abnormalities in eight patients, linear antral erosions in 10 patients, and small prepyloric ulcers in two patients and no OV were detected. They were managed by pantoprazole infusion and cytoprotective agents.

Among the 11 patients with $\mathrm{GBS} \geq 6$ and OV metric score $2.8 \pm 0.8$, endoscopy revealed bleeding gastric ulcer in six patients, corporeal vascular ectasia in two patients, subcardiac Dieulafoy lesion in one patient, GAVE in two patients and no one showed OV. They were managed with argon plasma coagulation and pantoprazole infusion for gastric ulcers.

Among the 19 patients who showed GBS $\geq 6$ and OV metric score $6.9 \pm 1.1$, endoscopy revealed bleeding gastric ulcer in four patients, vascular ectasia in one patient, PHG in six patients, and eight patients (44.4\%) showed OV which were managed with rubber band ligation.

Among the 50 patients who showed GBS $\geq 6$ and OV metric score $12.3 \pm 1.9$, endoscopy revealed PHG grade III (mainly fundic) in three patients which is the cause of bleeding, and 47 patients (94\%) showed OV grade III-IV with variable grades of PHG. They were managed with band ligation and argon plasma coagulation where appropriate.

The accuracy of the scoring system including GBS and $\mathrm{OV}$ metric score in risk stratification and prediction of $\mathrm{OV}$ in the validation group was evaluated using ROC curve analysis as shown in Figure 5. The AUC value was 0.989 (95\% CI: $0-1, p=0.000$ ) at GBS $\geq 6$ and OV metric score

Table 6 Prevalence of OV in study population according to summed OV cirrhometric score

\begin{tabular}{lllll}
\hline OV score & $\begin{array}{l}\text { Low risk (0-4) } \\
(\mathbf{n = 1 5 6 )}\end{array}$ & $\begin{array}{l}\text { Intermediate (5-8) } \\
(\mathbf{n = 6})\end{array}$ & $\begin{array}{l}\text { High (9-13) } \\
(\mathbf{n = 7 2})\end{array}$ & $\begin{array}{l}\text { Very high (14-17) } \\
(\mathbf{n = 6 6 )}\end{array}$ \\
\hline GBS 0 & $6(3.8 \%)$ & 0 & 0 & 0 \\
GBS I & $30(19.2 \%)$ & 0 & 0 & 0 \\
GBS 3-6 & $48(30.7 \%)$ & 0 & 0 & 0 \\
GBS $>6$ & $72(46.3 \%)$ & 6 & 72 & 33 \\
Endoscopy & & $2(33.3 \%)$ & $68(94.4 \%)$ & $66(100 \%)$ \\
OV & 0 & Gll & GII:20, GIIl:36, GIV:12 & GIII:32, GIV:34 \\
OV grade & - & & & \\
\hline
\end{tabular}

Abbreviations: GBS, Glascow Blatchford score; OV, esophageal varices 


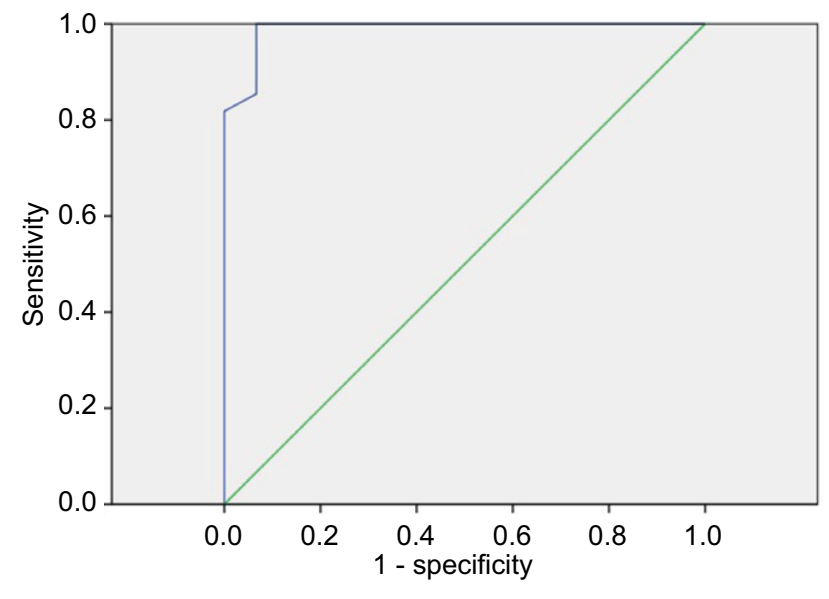

Figure 5 ROC curve for the prediction of $O V$ in validation group. Abbreviations: ROC, receiver operating characteristic; OV, esophageal varices.

$\geq 6.5$. It showed a sensitivity of $99 \%$ and a specificity of $97.2 \%$ in predicting OV presence and grade. GBS alone was not able to predict the presence of OV with the AUC value of $0.254, p=0.23$.

\section{Discussion}

Although patients with UGIB should perform upper GI endoscopy to declare the cause of bleeding, many patients showed that trivial symptoms such as gastric mucosal abrasions, congestion, or minute ulcers are the cause and could be managed medically, but may expose them to the hazards of endoscopy, especially, if there are associated systemic comorbidities, a critical issue discussed by Adamopoulos et al. ${ }^{32}$

It is a common situation for the high-risk patients to be presented with UGIB either due to their morbidity or the drugs given for their illness. It remains a challenge to select patients who will have the utmost therapeutic intervention benefit from upper GI endoscopy, the endoscopic triage.

Many patients with noncurable diseases, such as cardiopulmonary, renal, and neurological diseases, and elderly patients may be treated for long periods due to their illness without giving the attention to the underlying liver disease until they present with the first episode of UGIB.

The incidence of chronic liver disease has been growing, which is mainly due to viruses, alcohol, and fatty liver disease, so it is of major interest to apply noninvasive predictive tools to narrow the scope for identification of cirrhotic patients with significant portal hypertension. For example, as we experienced in patients presented with UGIB with prolonged INR due to the use of oral anticoagulants after valve replacement when presented with UGIB; after apply- ing GBS and OV metric score, the patients got benefit from endoscopic therapeutic intervention rather than deferring endoscopy depending on the usual belief that side effects of oral anticoagulants are a cause of bleeding.

Variceal metric score composed of clinical, laboratory, ultrasonographic, and Doppler data was accurate and precise in identifying patients with varices. The cutoff value of the score associated with the highest sensitivity and specificity was 8 in the study population (with a sensitivity of $98.5 \%$ and a specificity $76 \%$ ) and when applied to the validation group composed of critically ill patients who presented with UGIB.

GBS alone is useful in determining the patients who will need hospital-based intervention and is equivalent to the full Rockall score in predicting mortality and the need for endoscopic therapy, surgery, or blood transfusion. ${ }^{33}$ However, GBS alone cannot predict $\mathrm{OV}$ presence unless combined with $\mathrm{OV}$ metric score. A GBS $\geq 6$ and OV metric score $\geq 6.5$ showed a sensitivity of $99 \%$ and specificity of $97.2 \%$ in predicting OV.

Our study included a sufficient number of patients and a validation group. The clinical, laboratory and radiological variables selected in this study are easily collected and applicable, where the constellation of which has an accurate prediction of OV and when combined with GBS score make it novel way in critically ill patients and this enabled us to pick up the occult cases of bleeding due to OV or any serious underlying pathology and select with high degree of accuracy critically ill patients who will benefit from urgent endoscopy, thus avoiding many unnecessary risks on this category of patients.

Previous studies investigated noninvasive parameters such as splenomegaly, ascites and spider angiomata, ${ }^{34} \mathrm{CTP}$ class, ${ }^{35}$ platelet count, platelet count/spleen diameter ratio, ${ }^{36,37}$ serum albumin, and serum bilirubin ${ }^{38}$ however, they searched for limited number of variables with AUC (0.75-0.81). Our score showed an AUC value of 0.989 ; in addition, no one investigated the power of the noninvasive parameters for OV in critically ill patients.

Application of GBS and OV metric score in critically ill patients can be performed during the initial 12 hours of preparation before endoscopy.

A particular conclusion of our study is that GBS score $>2$, OV score $>4$, and cutoff value of 8 necessitates performing upper GI endoscopy whatever may be the associated medical illness, since endoscopy will be life saving as the cause of bleeding can be controlled. One direction for the future could be the integration of this approach in multicenters for the benefit of the critically ill patients and to minimize the burden on endoscopy units. 


\section{Acknowledgment}

The authors extend special thanks to residents of Internal Medicine and diagnostic radiology specialists - (Zagazig University) and Prof Ahmed Khaled Tawfik for their help and support in this work.

\section{Disclosure}

The authors report no conflicts of interest in this work.

\section{References}

1. Sharma VK, Nguyen CC, Crowell MD, Lieberman DA, de Garmo P, Fleischer DE. A national study of cardiopulmonary unplanned events after GI endoscopy. Gastrointest Endosc. 2007;66:27-34.

2. Gangi S, Saidi F, Patel K, Johnstone B, Jaeger J, Shine D . Cardiovascular complications after GI endoscopy: occurrence and risks in a large hospital system. Gastrointest Endosc. 2004;60:679-685.

3. Allison MC, Sandoe JA, Tighe R, et al. Antibiotic prophylaxis in gastrointestinal endoscopy. Gut. 2009;58:869-880.

4. Vogel SB, Rout WR, Martin TD, Abbitt PL. Esophageal perforation in adults aggressive, conservative treatment lowers morbidity and mortality. Ann Surg. 2005;241:1016-1021; discussion 1021-1023.

5. British Society of Gastroenterology. Guidelines on Complications of Gastrointestinal Endoscopy; 2006. Available from: http://www.bsgorg. uk/clinical-guidelines. Accessed November 14, 2017.

6. Stabile BE, Stamos MJ. Surgical management of gastrointestinal bleeding. Gastroenterol Clin North Am. 2000;29(1):189-222.

7. Martínez C, Blanco G, Ladero JM, et al. Genetic predisposition to acute gastrointestinal bleeding after NSAIDs use. $\mathrm{Br} J$ Pharmacol. 2004;141(2): 205-208.

8. Pimentel M, Roberts DE, Bernstein CN, Hoppensack M, Duerksen DR. Clinically significant gastrointestinal bleeding in critically ill patients in an era of prophylaxis. Am J Gastroenterol. 2000;95: 2801-2806.

9. Garcia-Tsao G, Sanyal AJ, Grace ND, Carey W. Practice Guidelines Committee of the American Association for the Study of Liver Diseases; Practice Parameters Committee of the American College of Gastroenterology. Prevention and management of gastresophageal varices and variceal hemorrhage in cirrhosis. Hepatology. 2007;46(3):922-938.

10. Elwakil R, Reda MA, Abdelhakam SM, Ghoraba DM, Ibrahim WA.Causes and outcome of upper gastrointestinal bleeding in Emergency Endoscopy Unit of Ain Shams University Hospital.J Egypt Soc Parasitol 2011; 41(2):455-467.

11. Cappell MS. Hepatic disorders mildly to moderately affected by pregnancy: medical and obstetric management. Med Clin North Am. 2008;92:717-737.

12. Tan J, Surti B, Saab S. Pregnancy and cirrhosis. Liver Transpl. 2008;14:1081-1091.

13. Cappell MS, Abdullah M. Management of gastrointestinal bleeding induced by gastrointestinal endoscopy. Gastroenterol Clin North Am. 2000;29:125-167.

14. Veitch AM, Baglin TP, Gershlick AH, Harnden SM, Tighe R, Cairns S. Guidelines for the management of anticoagulant and antiplatelet therapy in patients undergoing endoscopic procedures. Gut. 2008;57:1322-1329.

15. Tseng PH, Liou JM, Lee YC, et al. Emergency endoscopy for upper gastrointestinal bleeding in patients with coronary artery disease. $\mathrm{Am}$ J Emerg Med. 2009;27(7):802-809.

16. Liang CC, Wang SM, Kuo HL, et al. Upper gastrointestinal bleeding in patients with CKD. Clin J Am Soc Nephrol. 2014;9(8): 1354-1359.

17. Yorioka N, Hamaguchi N, Taniguchi Y, et al. Gastric antral vascular ectasia in a patient on hemodialysis improved with CAPD. Perit Dial Int. 1996;16(2): 177-178.

18. Clarke GA, Jacobson BC, Hammett RJ, Carr-Locke DL. The indications, utilization and safety of gastrointestinal endoscopy in an extremely elderly patient cohort. Endoscopy. 2001;33:580-584.
19. Romagnuolo J, Cotton PB, Eisen G, Vargo J, Petersen BT. Identifying and reporting risk factors for adverse events in endoscopy. Part I: cardiopulmonary events. Gastrointest Endosc. 2011;73: 579-585.

20. Child C, Turcotte J. Surgery and portal hypertension. In: Child CG, editor. The Liver and Portal Hypertension. Philadelphia: Saunders; 1964;50.

21. Stanley AJ, Ashley D, Dalton HR, et al. Outpatient management of patients with low-risk upper-gastrointestinal hemorrhage: multicentre validation and prospective evaluation. Lancet. 2009;373: $42-47$.

22. Goyal AK, Pokharna DS, Sharma SK. Ultrasonic measurements of portal vasculature in diagnosis of portal hypertension: a controversial subject reviewed. J Ultrasound Med. 1990;9: 45-48.

23. Senecal B. Sonographic anatomy of the normal spleen, normal anatomic variants, and pitfalls. In: Bruneton JN, editor. Ultrasonography of the Spleen. Berlin: Springer-Verlag; 1988;1-13.

24. Zhou HY, Chen TW, Zhang XM, et al. The diameter of the originating vein determines esophageal and gastric fundic varices in portal hypertension secondary to posthepatitic cirrhosis. Clinics (Sao Paulo). 2012;67(6):609-614.

25. Schepis $\mathrm{F}, \mathrm{Cemmà} \mathrm{C}$, Niceforo $\mathrm{D}$, et al. Which patients should undergo endoscopic screening for esophageal varices detection? J Hepatol. 2001;33:333-338.

26. Moriyasu F, Nishida O, Ban N, Uchino H. Congestion Index of the portal vein. AJR Am J Roentgenol. 1986;146:735-739.

27. Plestina S, Pulanic R, Kralic M, Plestina S, Samarzija M. Color Doppler ultrasonography is reliable in assessing the risk of esophageal variceal bleeding in patients with liver cirrhosis. Wien Klin Wochenschr. 2005; 117:711-717.

28. Colli A, Fraquelli M, Pometta R, Cocciolo M, Visentin S, Conte D. Renovascular impedance and esophageal varices in patients with ChildPugh Class A. Radiology. 2001;219:712-715.

29. Paquet KJ. Prophylactic endoscopic sclerosing treatment of esophageal wall in varices: a prospective controlled trial. Endoscopy. 1982;14:4-5.

30. El-Sayed AM. Noninvasive Prediction of Esophageal Varices in Patients with Compensated Cirrhosis [master's thesis]; 2005. Available from: srv4.eulc.edu.eg/eulc_v5/Libraries. Accessed November 14, 2017.

31. Sullivan LM, Massaro JM, Agostino BD. Presentation of multivariate data for clinical use: the Framingham Study risk score functions. Stat Med. 2004;23:1631-1660.

32. Adamopoulos AB, Baibas NM, Efstathiou SP, et al. Differentiation between patients with acute upper gastrointestinal bleeding who need early urgent upper gastrointestinal endoscopy and those who do not. A prospective study. Eur J Gastroenterol Hepatol. 2003;15(4): 381-387.

33. Stanley AJ, Dalton HR, Blatchford O, et al. Multicentre comparison of the Glasgow Blatchford and Rockall scores in the prediction of clinical end-points after upper gastrointestinal haemorrhage. Aliment Pharmacol Ther. 2011;34:470-475.

34. Thomopoulos KC, Labropoulou-Karatza C, Mimidis KP, Katsakoulis EC, Iconomou G, Nikolopoulou VN. Non-invasive predictors of the presence of large esophageal varices in patients with cirrhosis. Dig Liver Dis. 2003;35:473-478.

35. Zaman A, Becker T, Lapidus J, Benner K. Risk factors for the presence of varices in cirrhotic patients without a history of variceal hemorrhage. Arch Intern Med. 2001;161:2564-2570.

36. Giannini E, Zaman A, Kreil A, et al. Platelet count/spleen diameter ratio for the noninvasive diagnosis of esophageal varices: results of a multicenter, prospective, validation study. Am J Gastroenterol. 2006; 101:2511-2519.

37. Abd-Elsalam S, Habba E, Elkhalawany W, et al. Correlation of platelets count with endoscopic findings in a cohort of Egyptian patients with liver cirrhosis. Medicine. 2016;95(23):e3853 .

38. Bressler B, Pinto R, El-Ashry D, Heathcote EJ. Which patients with primary biliary cirrhosis or primary sclerosing cholangitis should undergo endoscopic screening for esophageal varices detection. Gut. $2005 ; 54: 407-410$. 
Clinical and Experimental Gastroenterology is an international, peerreviewed, open access, online journal publishing original research, reports, editorials, reviews and commentaries on all aspects of gastroenterology in the clinic and laboratory. This journal is included on PubMed. The manuscript management system is completely online and includes a very quick and fair peer-review system, which is all easy to use. Visit http://www.dovepress.com/testimonials.php to read real quotes from published authors.

Submit your manuscript here: https://www.dovepress.com/clinical-and-experimental-gastroenterology-journal 